\title{
Growth, competitiveness and employment in Peru, 1990-2003
}

\author{
Norberto E. García
}

$\mathrm{T}$

he growth of high-quality employment needed to reduce the share of informal occupation and open unemployment in Peru will require an acceleration and diversification of private investment in the tradable sector. One of the main constraints faced is the uncompetitiveness of the non-extractive tradable sector. In 1990-2003, competitiveness improved in this sector essentially as a result of lower labour costs, a socially unjust and economically ineffective route to follow. To raise competitiveness, it is essential for the macroeconomic regime to include a competitive real exchange rate (to which there are obstacles) and higher productivity at the microeconomic level. This latter goal needs to be pursued through microeconomic and mesoeconomic policies, the main obstacle being the narrow outlook prevailing from the mid 1990s onward, which emphasized the reduction of average labour costs as the main way to raise competitiveness.

Associate Researcher,

Peruvian Studies Institute (IEP)

and Research Leader.

Employment Policies Network of the

Economic and Social Research

Consortium (CIES),

Peru

œngarcia@terra.com.pe 


\section{I \\ Employment, poverty and growth}

In Peru there is a close link between the type of jobs generated and the poverty trends. In medium- and lowincome families, the earnings of working members are the main source of income. It should be no surprise that poverty has persisted at very high levels, then, since most of the jobs generated in the 1990s were of very low quality in terms of productivity, earnings, stability and the social protection that went with them. In that decade, formal employment grew at an annual rate of $1.2 \%$ but informal employment by $4.7 \%$, intensifying the trend seen in earlier decades.

At present, less than $25 \%$ of economically active Peruvians have access to a stable job that is productive enough to afford them a decent remuneration. The other $75 \%$ work in informal self-employment activities with very low productivity, in even less productive farm work or as wage earners without labour contracts in informal microenterprises that offer neither stability nor decent pay, or they are openly unemployed in the country's urban areas. It is important to note that only some $10 \%$ of these $75 \%$ are openly unemployed, while most of the other $90 \%$ work in very low-productivity occupations. Consequently, the employment problem in Peru is not perceived by the population as being mainly one of open unemployment. Rather, people have a very low expectation of obtaining a decent, stable job that will improve their standard of living.

As for earnings from labour, wages fell by $65 \%$ between 1980 and 1991. Although there was a recovery in 1992-1997, by 2000 they were still far below their 1980 level, and most informal and agricultural workers were earning less than the poverty line per active person. As a share of gross domestic product (GDP), remunerations fell from $37 \%$ in 1978 to $32 \%$ in 1992 and $24.5 \%$ in $2001 .^{1}$

These figures indicate that the employment problem in Peru cannot be addressed solely with shortterm policies, active employment policies and direct employment programmes, which by their nature do not reach more than $5 \%$ or $6 \%$ of the economically active population (EAP). A medium- and long-term policy is therefore needed, i.e., a growth strategy.

In the medium term, the expansion of high-quality employment is determined by the rate of investment growth. To increase high-quality employment in modern segments and make resources available to modernize production methods in unreformed traditional segments and improve the lot of those working there, it will be necessary to speed up investment and economic growth.

\section{II}

\section{Recent macroeconomic policy}

The administration that took office in mid-2001 inherited a recession that had begun in 1998 and deepened in the following years until early 2002. From mid-2001 onward a recovery policy was implemented, including a measured increase in public spending and an expansionary monetary policy that focused on lowering the domestic interest rate. This policy was successful in bringing the country out of recession without raising inflation, but it did little to improve competitiveness. As this reactivation took effect and new extractive investment projects came on stream, GDP grew by $4.9 \%$ in 2002 and 4\% in 2003 (INEI, 2004).
Not only did public spending increase, but in 2001-2003 the fiscal deficit came down owing to rising tax revenues and, above all, to public-sector external borrowing in 2002-2003; this heightened the country's financial and real vulnerability to any rise in international interest rates.

\footnotetext{
${ }^{1}$ Three shocks account for this tendency: the debt crisis of the early 1980s, the hyperinflation of 1989-1990 and the labour deregulation that effectively ensued from the reforms to make employment more "flexible" in the 1990s.
} 
It was thought that economic recovery driven by higher public spending and lower interest rates, combined with a policy of macroeconomic balance and price and real exchange-rate stability (via a dirty float), would open the way for higher private-sector investment. Nonetheless, total gross investment, which had fallen by $26 \%$ in 1997-2001, grew by just $0.7 \%$ in 2002 and $4 \%$ in 2003, a year when the total gross investment ratio stood at $15.2 \%$ of GDP. This was some 10 percentage points less than was necessary to attain the annual economic growth of $7 \%$ required to make inroads into the employment problem. In particular, monthly imports of capital goods remained low in 2001-2003, despite the fact that they included demand from the large Antamina and Camisea projects, ${ }^{2}$ and the monthly investment records for the construction sector tell the same story. The weakness of private-sector investment is explained in part by the slowdown of the main economies of the North in 1999-2002. As will be seen later, however, there were also further-reaching domestic reasons.

The boost provided by higher public spending and monetary expansion in 2001 and 2002 tended to tail off over time. Since late 2003 there has been a further slowdown in GDP and employment, despite the liquidity in the economy. The sudden rise in exports in early 2003 (the rate for the year was $15 \%$ ) partly offset the weakening in the effects of the country's expansionary public spending and monetary policy. Since $70 \%$ of this increase was due to higher prices and volumes for Peru's traditional commodity exports, it is difficult to regard the improvement as permanent, although it is true that non-traditional exports have been growing rapidly as well.

The expansion generated by the reactivation measures in 2001-2002 produced very low growth in formal employment and a high expansion in informal employment, in line with the very low growth of private and public investment and with long-term trends. The absence of any strong investment boost meant that high-quality employment increased only very modestly.

These circumstances give a new urgency to the debate about what course needs to be taken and what policies adopted to boost private-sector investment and achieve steady growth in high-quality employment. The present work contributes with a hypothesis to this debate, focusing on the modern formal sectors of the Peruvian economy, since the main obstacle to high and sustainable growth lies there. High growth in modern segments is a necessary but not sufficient condition for productive transformation and growth in more backward segments. At least, this seems to be the experience of Chile (1983-2003) and Mexico (19862003), among others.

\section{III}

\section{A strategic course}

The Peruvian economy faces two urgent problems: its poor competitiveness, and the need to create highquality employment. Consequently, any growth strategy necessarily has to address both issues.

In a small, open and indebted economy like Peru's, this means applying macroeconomic, mesoeconomic and microeconomic policies to: i) accelerate privatesector investment decisions in tradable sectors (producers of exportable and importable goods and services), and ii) expand the markets for these goods and services. From a strategic standpoint, the important thing is how policies at the three levels are combined (García, 2004).

\footnotetext{
2 Antamina mining company and Camisea gas field.
}

As has occurred in other Latin American countries, Peru has integrated far more fully into international financial markets (through borrowing and capital inflows) than into international trade, where it remains essentially an exporter of commodities subject to price and quantity fluctuations. This imbalance in its external profile needs to be corrected if the country is to speed up export growth, achieve rapid economic expansion, reduce the burden of debt payments and create jobs. For exports to grow faster, it is useful to know which are the most dynamic in world markets, i.e., to consider the quality of the trade profile and not just the coefficient of openness (Svarzman, 2004).

In 1990-2000, world exports of commodities (which are what Peru exports) grew more slowly than all other categories. This holds true if they are 
compared to high-technology exports, which are knowledge- and capability-intensive and grew fastest in the period; with intermediate-technology exports, whose products and processes are based on economies of scale and which grew faster than average; or even with low-technology exports, such as wearing apparel and footwear, or natural resource-intensive manufacturing (Svarzman, 2004). Only the strong demand for extractive commodities resulting from high growth in China began to change this tendency in 2003, by straining the supply of commodities. Nonetheless, this development is unlikely to mean a permanent change in the structural tendencies underlying commodity exports.

Consequently, economic policy needs to create the conditions for consolidating the progress made with exports and gradually encouraging the production of goods and services with greater value-added and for which international demand is stronger. Particularly important for Peru are exports of goods and services that are natural resource-intensive but have one or more processes that increase their value-added by incorporating a higher employment content and improved backward employment linkages.

The priority is rapid growth of private-sector investment in non-extractive tradable (and particularly exportable) products. The steadily rising availability of foreign currency that would ensue is a necessary but not sufficient condition, in an economy with external debts like Peru's, for faster growth of investment in non-tradable products, and thus of aggregate investment in modern sectors generally. It must be stressed that non-tradable sectors will not be boosted automatically (as the experience of Mexico in 19942002 shows) and that actions and policies are required to achieve this.

In turn, high and sustained growth of private investment in tradable products, when accompanied by rising private investment in non-tradable products in modern segments, enables a rapid creation of highquality jobs in modern segments and provides the resources needed for productive transformation in traditional segments, if the country succeeds in enhancing productive transformation policies and linking traditional sectors to the growth in modern ones.

Preliminary estimates calculated for this study show that to achieve high-quality employment growth of $4 \%$ annually over the coming years (and this is the minimum needed to absorb high EAP growth in modern segments and significantly reduce informal working over a reasonable time scale), private investment in tradable sectors will need to rise by about $8 \%$ a year, entailing annual export growth of almost $9 \%$. These figures are compatible with sustained GDP growth of $7 \%$ a year. ${ }^{3}$

Sustained private investment growth in tradable sectors of just over $8 \%$ a year, accompanied by annual investment growth of $7 \%$ a year in non-tradable sectors, would bring significant results in 20 years: the volume of high-quality employment would almost triple, thanks to the creation of more productive new jobs and the rise in real remunerations resulting from higher productivity. Given the high growth rate expected in the total EAP (over $2.6 \%$ a year), the proportion of people working in very low-productivity occupations would fall from $67 \%$ to about $39 \%$. Parallel policies would be needed to transform and improve the productivity of those still working in such occupations.

While it is stressed, rightly, that the decisive factors for speeding up private investment are: i) macroeconomic balances, ii) stable ground rules for private investment, iii) legal security and iv) the credibility of the government and country and the confidence they inspire, a fifth, omitted factor also needs to be considered: competitiveness, which determines the rate of return on private-sector investment. This rate has to be high enough for firms to invest at the rapid rate required.

High returns in non-extractive tradable sectors are essential to attract new ventures and diversify investment there, an important issue for a country where private investment is largely confined at present to mining, industrial fishing and oil and gas. High returns are also needed so that some of them can be passed on in the form of lower prices and higher quality. From a longterm perspective, non-extractive tradable sectors gradually need to become profitable enough to induce high growth in private investment there.

\footnotetext{
3 The projections given in the text were prepared using the reduced expression of the model presented in full in García (2002a). This is a macroemployment model that distinguishes between a tradable sector and a non-tradable one and incorporates functions that adjust the return on private investment by the real exchange rate and overall productivity. Investment in tradable and non-tradable sectors depends on the returns and expected demand growth of tradable products. The increase in investment in each sector determines the mediumterm growth of employment, given the increase in the overall productivity of each sector already referred to. The model distinguishes between a high-quality employment sector associated with the behaviour of the tradable and non-tradable sectors, and a low-quality employment sector associated with underdeveloped rural and urban segments.
} 
In the case of Peru, increasing the rate of return essentially depends on raising the competitiveness of firms and the country at large. Competitiveness is determined by the real exchange rate and overall productivity at the microeconomic level (that of all the resources used by firms), including productive infrastructure and other factors in the microeconomic environment. To raise returns in non-extractive tradable sectors to the required level, it is indispensable: i) to have a competitive real exchange rate in order to spark investment in non-extractive tradables; ii) to start closing the productivity gap between Peru and competitor countries. Raising productivity at the microeconomic level reduces total unit costs, creates scope for quality improvements and enhances investment returns. Since this process operates with a time lag, however, it is important to have a competitive real exchange rate at the outset, as this can be achieved more quickly and maintained until sustainable growth in overall productivity takes the leading role.

While high returns are a necessary condition, they are not sufficient. To raise expectations and inject dynamism into private-sector investment decisions in a situation like the present one, it will be necessary to make large institutional changes that encourage these decisions. The new external trade agreements can fulfil this role.

In practice, the need is to stimulate local privatesector investment decisions, since a very high proportion of the investment hoped for will be domestic and not external.

\section{IV}

\section{Private investment growth, the real exchange rate and productivity}

In a context like Peru's, the rate of return in nonextractive tradable sectors is determined essentially by the real exchange rate and by productivity growth at the microeconomic level. Let us see how these variables have behaved in the recent past.

\section{The real exchange rate}

As figure 1 shows, Peru's real multilateral exchange rate has strengthened persistently. From early 1985 to early 2003 it strengthened by about $64 \%$, according to the statistical series of the Central Reserve Bank of Peru, while from 1985 to 1992 its value increased by $73 \%$, the year of comparison taken in this case being one subsequent to the 1990 shock programme. Going back to the late 1970 s, we also find a substantial appreciation of $70 \%$ between 1978 and 1995 (Moguillansky, 1996). Even if the hyperinflation of 1989-1990 distorted the data and the actual appreciation of the real exchange rate was less than the statistical series show, it is undeniable that the real multilateral exchange rate strengthened significantly between 1978 and 1992, because a large appreciation had already been seen prior to 1990 (in 1978-1989). From 1992 to 1994 it fell back somewhat and from
FIGURE 1

Peru: Real exchange rate, 1985-2003a

(Real excahge rate indice, 1994=100)

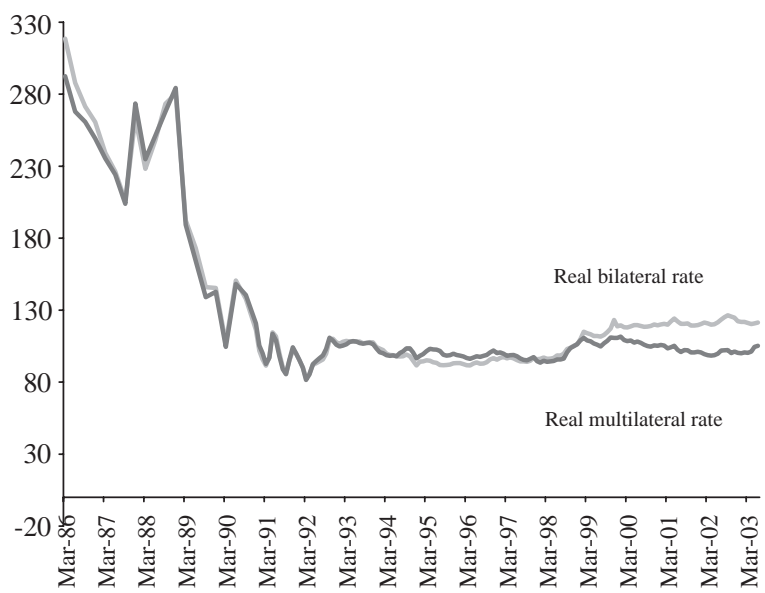

Source: Statistical series, monthly bulletins and database of the Central Reserve Bank of Peru (BCRP).

a The real exchange rate is defined for present purposes as the ratio between external and internal prices, multiplied by the nominal exchange rate.

then onward, with fluctuations, tended to remain stable until 2002. In 2003 the Central Reserve Bank 
successfully tracked the weakening dollar, resulting in a partial correction of the real multilateral exchange rate.

The price ratio between tradable and non-tradable products, as measured by the Central Reserve Bank index, fell by $68 \%$ in $1985-2002$, thus confirming that the appreciation of the real exchange rate substantially reduced the average returns on non-extractive tradables, even if the hyperinflation of 1989-1990 may have caused the extent of the fall to be overestimated. The outcome of this tendency has been a worsening of relative prices for the industrial, agriculture and tourism sectors, with adverse effects on profitability in each of them. In the Peruvian economy, both agriculture and tourism are major currency earners and sources of direct and indirect employment.

It should be noted that objections to a weaker real exchange rate on the grounds of its adverse impact on real wages cease to hold when the depreciation is gradual and the rate of productivity growth offsets the effect on real wages.

\section{Total productivity}

The second important factor in profitability is the behaviour of overall productivity at the microeconomic level. The productivity of all the resources used by businesses matters here, as does the availability of competitiveness-critical infrastructure. The indicators available are macroeconomic and are thus an aggregate of microeconomic situations.

As table 1 shows, all the empirical studies available reveal very slow or even negative overall productivity growth in 1970-1990, followed by a small rise in 1990-1997, estimates of which vary from author to author, but which amounted to approximately $1 \%$ a year. After 1997, the recession that affected the country in 1998-2001 very probably led to a drop in overall productivity. A recent World Bank study (De Ferranti and others, 2003) confirms the results given for the 1970 s and 1980s and estimates total productivity growth of $0.7 \%$ a year in 1991-1997. Consequently, between 1970 and 2000 the net long-term trend for total productivity was one of virtual stagnation. This happened at a time when many competitor countries (China, Chile, Japan, the Republic of Korea, the United States and others) were highly productive and/or were making substantial progress in this respect, with productivity growing by between $1 \%$ and $5 \%$ a year. A recent study (García, 2002a) concludes that the medium-term stagnation of productivity took place in all sectors except mining.

An indicator which confirms this total productivity trend is the long-term behaviour of investment in machinery and equipment as a proportion of GDP. According to Iguiñiz (2001), this indicator fell from $24 \%$ in 1975 to approximately $8.6 \%$ in 2001 . Long-term capital accumulation in machinery and equipment is a significant indicator in itself, given its effect upon the composition of the capital stock and thence upon overall productivity. But it is also important because it is normally complemented by other key variables which form part of the capital stock. This stock, broadly defined, includes the long-term growth of the skilled portion of the workforce, the spread of management criteria in relation to productivity and competitiveness, the growth of all the specific forms of know-how required to improve productivity, the introduction of soft and hard technological innovations, and other aspects. To put it another way, the fall in the proportion of GDP going to

TABLE 1

Peru: Estimates of total factor productivity, 1950-1959 to 1991-2000

(Average annual change, percentages)

\begin{tabular}{|c|c|c|c|c|c|c|}
\hline Period & IPE & $\begin{array}{c}\text { Beltrán and } \\
\text { Seminario } \\
\text { (1998) }\end{array}$ & $\begin{array}{c}\text { Vega } \\
\text { Centeno } \\
(1989)\end{array}$ & $\begin{array}{c}\text { Vega } \\
\text { Centeno } \\
(1997)\end{array}$ & $\begin{array}{c}\text { Vallejos and } \\
\text { Valdivia } \\
(1999)\end{array}$ & $\begin{array}{c}\text { Calvo and } \\
\text { Bonilla } \\
(1998)\end{array}$ \\
\hline $1950-59$ & $1.5^{\mathrm{a}}$ & 1.0 & 1.5 & 1.1 & 2.7 & $\ldots$ \\
\hline $1960-69$ & $1.4^{\mathrm{b}}$ & 2.5 & 2.0 & 1.3 & 1.7 & $\ldots$ \\
\hline $1970-80$ & $-0.8^{\mathrm{c}}$ & 0.3 & 1.1 & -0.8 & -0.6 & $\ldots$ \\
\hline $1981-90$ & -3.9 & -3.6 & $0.3^{\mathrm{d}}$ & -2.4 & $-4.0^{\mathrm{e}}$ & $\ldots$ \\
\hline $1991-2000$ & 1.0 & $3.4^{\mathrm{f}}$ & $\ldots$ & $-0.4^{\mathrm{g}}$ & $1.8^{\mathrm{h}}$ & $1.8^{\mathrm{i}}$ \\
\hline
\end{tabular}

Source: Peruvian Institute of Economics (IPE, 2001).

a 1951-1960. b 1961-1970. c 1971-1980. d1981-1988. e 1980-1990. f 1991-1995. g 1991-1996. h 1991-1998. i $1993-1996$. 
investment in machinery and equipment is signalling that other factors crucial for raising productivity, like those listed, are also being affected or neglected. This is confirmed by Iguiñiz (2001) himself when he states that real public spending on education per pupil, used as a proxy for the quality of education spending on the lowest-income $80 \%$, fell steadily from the late 1960 s onward and is now less than half its 1968 level.

Porter's (2003) empirical analyses also confirm this by showing that Peru is one of the more backward countries when microeconomic competitiveness is considered, as will be seen later.

To sum up, tendencies in the real exchange rate and overall productivity resulted in a long-term decline in returns in non-extractive tradable sectors.

Thus, when tariffs were reduced and administrative controls lifted in the early 1990s, the real exchange rate was appreciating and overall productivity was very low. All of this undoubtedly had an impact on effective protection and the profitability of tradable sectors, and the safety valve was the reduction of average labour costs. As will be seen in a later section, the reduction of these costs only partially offset the combined effect of the strengthening real exchange rate, trade liberalization and stagnant productivity. Although it did permit the survival and emergence of some tradable activities whose productivity gave them a competitive edge, it was not enough to give any significant impetus to investment diversification in exportables and in competitive import substitution, and this had severe effects on employment.

To put it another way, the trends described meant that the effective protection rate on profits fell significantly in tradable activities, affecting returns. Sectors such as mining, oil and fishing did not suffer ill effects, as their profitability depends more on the characteristics of the natural resource they exploit.

\section{The real exchange rate and competitiveness}

At present, it is generally held that the real multilateral exchange rate should remain stable. In fact, it has been fairly stable since 1994, albeit with fluctuations. The exception was 2003 when, as noted earlier, the devaluation of the dollar affected the real exchange rate because the Central Reserve Bank managed to track it down against other currencies.

There are a number of reasons for the stability of the real exchange rate. The following can be highlighted: i) when the economy was opened up in the early 1990s the Central Reserve Bank was struggling to control hyperinflation, and used the nominal exchange rate as an anchor; ii) in 1990-1998, the Central Reserve Bank accepted that improving competitiveness depended, as the Government maintained, on reducing labour costs and improving infrastructure, and not on the real exchange rate; iii) the Peruvian economy generates currency from large-scale traditional extractive commodity production and from illegal activities and crops, so that the equilibrium exchange rate which balances the external accounts tends to be stronger than the rate needed to achieve high returns in non-extractive tradable sectors; iv) the goal of a stable real exchange rate became entrenched in the business and economist culture of the 1990s, but little thought was given to how competitive this rate was or what effect the 1980-1992 appreciation might have had; v) in the late 1990s, heavy private- and public-sector currency borrowing led to a situation in which a real devaluation would have caused instant losses for many businesses, increased the fiscal cost of public external debt servicing and gravely undermined confidence in the country; vi) the recessionary syndrome affecting many companies' investment decisions has resulted in weaker currency demand, and vii) currency inflows in financial accounts were only regulated in early 2004.

These factors do not justify the failure to establish a competitive real exchange-rate regime, but they do explain why in practice the Central Reserve Bank had to be very active in the currency market to prevent the real bilateral exchange rate from strengthening against the dollar. In fact, in 2002, 2003 and the early months of 2004 the Bank made large net purchases of foreign currency, constituting a very high proportion of international reserves. Then in March 2004, for the first time since financial liberalization, it had to introduce a capital-account regulation establishing a $20 \%$ reserve requirement for external credits. 
The main point, however, is that it is not feasible to alter exchange-rate policy in isolation. It would be necessary to change the macroeconomic regime in its entirety, aligning monetary, fiscal and exchange-rate policy to defend not only an inflation target, as is done now, but also a target for a competitive real exchange rate. ${ }^{4} \mathrm{~A}$ competitive real exchange rate can only be achieved and maintained if exchange-rate, monetary and fiscal policies are closely coordinated in pursuit of the two intermediate objectives described, and if unorthodox instruments are used to regulate large-scale movements of short-term capital and, in situations of crisis, to prevent currency flight. By definition, as Frenkel (2004) points out, an expansionary macroeconomic policy in a small, open economy with large external debts depends on a competitive real exchange rate, and not on expansionary monetary and fiscal policies. ${ }^{5}$ Consequently, while a gradual weakening of the real exchange rate would be desirable, in Peru this would only be viable if the macroeconomic regime as a whole were altered, and not just exchange-rate policy. A change as far-reaching as this is particularly unlikely in present circumstances, since the prevailing strategy is the opposite: a stable and uncompetitive real exchange rate, and expansionary monetary and fiscal policies.

Delaying exchange-rate adjustment affects not just non-extractive exportable output, but also output that competes with imports, which is oriented towards the home market and creates a great many jobs.

Unless the real exchange rate weakens, the only way to improve competitiveness is to reduce unit costs and/or increase overall productivity at the microeconomic level. When the exchange rate is expected to weaken very slowly or not at all, there is additional pressure for rapid total productivity growth, as this will be needed to boost competitiveness in a world where many countries are devaluing and all are striving to raise their productivity.

\section{VI}

\section{Average labour costs versus total unit costs}

In the 1990s, efforts were made to raise competitiveness partly by improving infrastructure, but mainly by reducing average labour costs. By the average labour cost is meant the total labour cost per unit of work (hours, weeks, months), and by unit labour cost is meant the total labour cost per unit of output.

The adjustment to the external debt crisis of the early 1980s, and the impact of hyperinflation in 19891990 , drove real remunerations down by $65 \%$. Consequently, the trade liberalization of the early 1990s was underpinned by very low labour costs, and over the course of the decade average remunerations

\footnotetext{
${ }^{4}$ Frenkel (2004), Ball (1998), Rodrik (2003) and Williamson (2003).

${ }^{5}$ Following Frenkel (2004), we would say that a stable, competitive real exchange rate helps to increase employment in three ways: i) by making tradable sectors more profitable, which increases net exports, investment and the growth rate in the medium term; ii) by lowering the cost of the domestic and labour components of output and increasing the cost of imported components and equipment (which affects tradable and non-tradable sectors), and thereby increasing employment-output elasticity, and iii) by playing a preventive role and limiting job losses when external shocks occur.
}

recovered only very slowly, so that by 2000 they were still 20\% lower than in 1980.

Although non-wage labour $\operatorname{costs}^{6}$ fell and statutory redundancy payments were reduced, the main factor bearing down on costs in the 1990s was the labour reform and the behaviour this induced. By introducing flexible contracts (multiple contracts that cost less than stable ones) and effectively reducing workers' bargaining power, labour reform directly influenced average labour costs; but it also led to deregulatory behaviour (wage employment without labour contracts) that likewise affected these costs (figure 2).

The main course adopted was to transfer a majority of wage earners to cheaper contracts.

\footnotetext{
${ }^{6}$ In Peru, non-wage labour costs (sobrecostos laborales) are defined as all the items that are added to the cost of wages to arrive at the employer's cost of labour. They include a notional amount for vacations and public holidays, the payroll solidarity tax, the employer's contribution to length of service payments, contributions for occupational health and injury insurance, and other non-wage labour costs.
} 
FIGURE 2

Private-sector wage earners by employment contract, 1991-2001

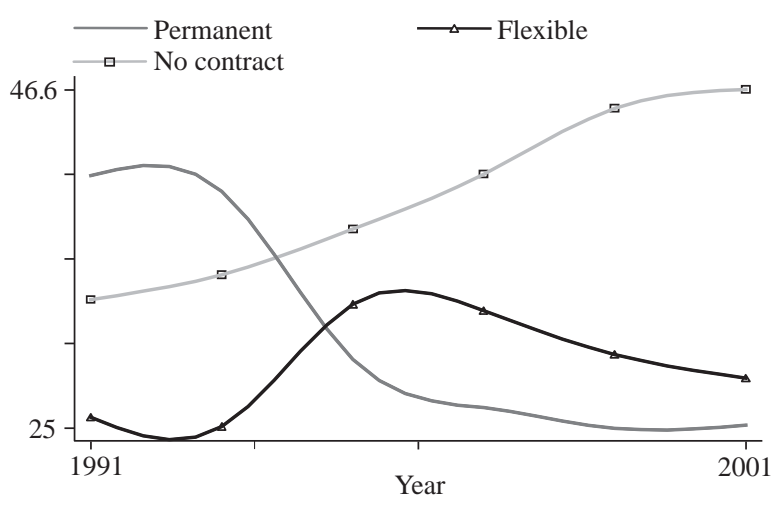

Source: Chacaltana and García (2002); National Institute of Statistics and Informatics (INEI), National Household Survey, third quarter (various years).

According to Martínez and Tokman (1999), around 1996 the cost of employing someone in industry on a permanent basis was US\$ 2.1 per hour, but the figure was only US\$ 1.37 for those with short-term contracts and US\$ 1.1 for those without contracts. ${ }^{7}$ Figure 2 shows that between 1991 and 2001 the proportion of wage earners with temporary (flexible) contracts rose to $32 \%$, as was to be expected after the reform. Paradoxically, though, the proportion of wage earners without contracts rose by far more, to $47 \%$ in 2000 .

The large rise in the proportion of wage earners without contracts in the private sector was due to an increase in evasion (to reduce costs) and to the rise in the proportion of private-sector wage earners working in small firms and microenterprises. Evasion tends to be more widespread in these companies than in medium-sized and large ones.

Owing to these tendencies, the proportion of private-sector wage earners with stable contracts fell to $21 \%$ in 2000: $79 \%$ of the country's private-sector wage earners had short-term contracts or none at all.

The massive transfer of wage earners to less costly contracts cut average labour costs by $14 \%$, equivalent to a one-off drop of $4.7 \%$ in total unit costs (García, 2002a). Even if it did provide a safety valve, then, the

\footnotetext{
7 Wage earners without contracts are defined statistically as those who do not declare an employment contract or social security, health or pension contributions in household survey responses.
}

drop in labour costs was wholly insufficient to offset the pressure generated by the rise in the real exchange rate, the reduction of tariff protection and controls, and the stagnation of productivity.

The reduction in average labour costs led to a considerable increase in precarious employment and to underlying labour unrest that became manifest in the early years of the transitional and democratic Governments. This created a severe problem for the incipient export model, as became apparent in 2002 and 2003.

In essence, this problem is one not just of social justice, but of economic efficacy as well. By contrast with the very modest reduction in total unit costs that can be obtained through a controversial reduction in labour costs, a steady increase in productivity of $2 \%$ to $4 \%$ a year causes unit costs to fall by about $25 \%$ over seven years. Cutting non-wage labour costs can make a contribution, but it cannot be the main basis for a significant rise in medium-term competitiveness.

Reducing non-wage labour costs is insufficient: i) because unit labour costs are a small fraction of total unit costs, given the dramatic fall in remunerations as a proportion of GDP in 1980-2000, and ii) because even with a large reduction in non-wage labour costs the one-off reduction in average labour costs that can be achieved is only $7 \%$ to $8 \%$, equivalent to a one-off reduction of about $3 \%$ in total unit costs. This gives an idea of what this strategy can achieve.

What has been said so far suggests that, going forward, the strategy of attaining competitiveness by cutting labour costs is a dead end. By contrast, a strategy based on a sustained rise in overall productivity to reduce total unit costs and improve product quality is more socio-politically viable, as improvements in competitiveness are not obtained at the expense of one actor or another and, above all, they are compatible with long-term growth in real wages, at a rate determined by the rate of productivity growth.

The issue, then, is not just the reduction of average labour costs and non-wage labour costs, a simplified approach that was used in the recent past and has lingered on until the present. The question is how we can rapidly commence a sustained effort to raise the productivity of all resources at the firm level and thereby achieve steady reductions in total unit costs and quality improvements. Martínez and Tokman (1997) propose the option of increasing labour productivity to reduce labour costs per unit in dollar terms, in order to raise competitiveness. In García (2002a) and in this article the stress is on increasing overall productivity to 
reduce total unit costs in dollars at the microeconomic level, including transaction costs and the infrastructure to facilitate investment, and a weakening of the real exchange rate to bring costs down in currency terms. In this proposal, then, lower labour costs result from higher labour productivity, but this is not the only factor bearing down on total unit costs, since by definition raising overall productivity means paying attention to all the main components of total unit costs, and a weakening of the real exchange rate reduces costs in currency terms.

Total costs per unit produced at the microeconomic level can be seen as the sum of the inputs needed per unit of output multiplied by the price of each input. An across-the-board reduction in the input required per unit of output (an increase in the productivity of each input) is the main way of reducing total unit costs and improving quality at the microeconomic level over the medium term. Hence, lowering total unit costs depends on increasing the productivity of all inputs (total productivity) at the microeconomic level.

One way of incorporating the required increase in total productivity as an objective of economic policy is to suppose that with the "right" short-run macroeconomic policy over successive short terms, the long-term adjustment process of markets will spontaneously generate a sustained increase in overall productivity. Nonetheless, Katz (2000), García (2002a) and Porter (2003) argue that deliberate actions and policies at the microeconomic level, and not just the macroeconomic level, are indispensable if successful modernization and productivity improvements are to be attained under today's conditions. It is not enough just to apply macroeconomic policies, because these have longer lags and Peru's social situation does not give us much time. There can be no delay, therefore, in adopting policies that have a significant effect at the microeconomic level in raising the overall productivity of businesses and improving the environment they operate in.

This approach does not ignore the need to transform the least advanced segments, in rural areas or in informal activities, even though this is not the subject of the present study. But in order to transfer resources to these segments so that they can achieve significant improvements in their productivity and incomes, it is essential for the more modern sectors to be able to grow very rapidly, thereby permitting a larger transfer of resources. Otherwise, transfers to raise the productivity of the least advanced segments will continue to be very small in relative terms, as they have been over the last 30 years. To speed up the growth of modern segments it is vital to raise the overall productivity of non-extractive tradable activities and establish a macroeconomic regime that includes a competitive, stable real exchange rate.

\section{VII}

\section{Export and employment growth}

Nonetheless, it needs to be stressed that while higher overall productivity may make the country more competitive, it does not in itself guarantee an increase in high-quality employment. To achieve this it is vital to combine productivity-raising policies with really effective measures to expand external markets and boost exports.

A small country, three quarters of whose active population are employed in very low-productivity activities or simply unemployed, does not have a dynamic domestic market to stimulate private-sector investment decisions in an open-economy context. If the real exchange rate weakens over the medium term, activities that compete with imports can be expected to perform better. But unless this happens, activities in tradable sectors that are oriented towards the domestic market are unlikely to be able to contribute much to faster growth until the effects of higher productivity in exportable sectors have played their part in dynamizing that market.

It is therefore necessary to apply a range of measures to remove obstacles to exports, diversify them and ensure that they grow much faster than productivity, i.e., at sustained rates of $8 \%$ to $9 \%$ a year over long periods. For the desired effect on employment to be attained, the rise in exports needs to precede, and then accompany, the rise in overall productivity.

It is worth recalling here that the starting point is the absolute and relative weakness of Peru with regard to exports. In 2001, per capita exports at constant prices 
were lower than in 1975, and in the early twenty-first century Peruvian exports continue to be dominated (almost $70 \%$ ) by commodities, mainly minerals and metals, just as they were 50 years ago.

Furthermore, exports are highly concentrated in three ways (Aráoz, 2002): i) 68\% are traditional products from industries such as mining, fishing, oil and gas and agriculture, although this last category has declined greatly so that it now accounts for just $5 \%$ of traditional exports; ii) $25 \%$ go to the United States, $24.9 \%$ to three European Union countries and Switzerland, and $15 \%$ to five Latin American countries (Brazil, Mexico, Colombia, Chile and Venezuela); and iii) $95 \%$ are generated by $12 \%$ of exporters. Consequently, policy should aim at diversifying exports by product type, destination market and exporter.

There are eight main issues for increasing exports: i) the negotiation of trade agreements, progress having been made with the signing of the Andean Trade Preference and Drug Eradication Agreement (ATPDEA) with the United States, the forthcoming negotiations with Brazil and Mercosur, and those now in progress with the United States, the European Union, Japan and China; ii) access to pre- and post-shipment credit and increasing use of the respective insurance policies and bonds; iii) the spread of product quality and classification norms; iv) the identification of markets, niches and standards for exported products, which will require a more powerful public-private strategy than any implemented so far; v) the spread of productivity and quality management practices to the majority of businesses, as they are currently confined to some 400 foreign and large domestic companies; vi) lower and more homogeneous tariffs, these having undergone major changes since 1992; vii) the development of production infrastructure, which involves speeding up the awarding of concessions to the private sector, and viii) the removal of obstacles to the development of the tourism sector.

Aráoz (2002) reminds us that in 1993-2002 there were eight substantive reforms to the tariff regime, resulting in a lowering of the original average rate and, more importantly, in large variations between the specific rates for different types of goods. In late 2002, the average tariff, weighted by imports, had been cut to $10.8 \%$, but the coefficient of variation of the tariff distribution had risen to almost $32 \%$. Furthermore, there are the temporary import surcharges ("safeguards") hastily imposed in 2003 to contain imports from China and other Asian countries. These changes are not the result of any programme but of one-off decisions intended to reduce the cost of importing intermediate inputs and capital goods or to raise the cost of consumer goods, and reflect initiatives to benefit local producers by this means, since the real exchange rate cannot be used for this purpose. Consequently, and paradoxically, a stable real exchange rate has been associated recently with a policy of variable tariff rates and surcharges to improve competitiveness by this second method.

As regards infrastructure, in 2002 the Peruvian Institute of Economics (IPE) estimated the amount of investment needed to bring port, airport, communications, motorway, road, energy and other infrastructure up to the standards currently found in Colombia or Chile (IPE, 2002a and 2002b).

To provide Peru by 2014 with an infrastructure similar to that existing in Chile and Colombia in 2002, investment of some US\$ 18.2 billion will be required over the decade, equivalent to 3\% of GDP over 10 years. Since the public sector does not have the financial, human and material resources necessary to meet this challenge, there is an urgent need to bring in a strategy of private-sector concessions, something that inexplicably has been in abeyance for the last four years.

A conservative estimate made for this study suggests that infrastructure investment of US\$ 18.2 billion would result in the direct creation of some 200,000 jobs lasting an average of one year apiece, distributed over 10 years, and the indirect creation of about 500,000 jobs, with some lag. This indicates that fostering private investment in public infrastructure that helped improve firms' productivity would create jobs not only because these firms' competitiveness would be enhanced, but also because the actual construction of the infrastructure would create a large amount of direct and indirect employment. This, then, is an activity that should be given priority.

Concerning the tourism sector, its development is a matter of priority for three reasons: i) it has enormous currency-earning potential; ii) it has a large direct and indirect effect on employment; iii) it is a sector that does not have barriers to entry related to know-how and major innovations, since the technical and organizational characteristics of the different activities making it up are already well known and understood in the country.

According to Chacaltana (2002), the development of tourism in Peru accelerated in 1992-1998, when the number of visitors tripled. In 1998 there were 600,000 tourists and currency revenue totalled US\$920 million. 
In 2003, despite the difficulties created by conflicts elsewhere in the world, the number of tourists rose to 900,000 and currency earnings from this source rose proportionately.

In the late 1990 s, even in the absence of any active policy to support the sector, tourism supplied $40 \%$ of all currency earnings from non-traditional exports. Tourism-related employment, meanwhile, grew very rapidly between 1992 and 1998, by 15\% a year. In 2000 tourism employed practically the same number of people as the construction industry, and $40 \%$ as many as manufacturing, even though tourism was only just beginning to be developed after many years of stagnation and the real exchange rate was not favourable. Being a net currency earner, again, tourism indirectly creates employment in other sectors. As a result, it has at least as much potential to create jobs as the construction sector, with the advantage over the latter that it is a tradable sector which contributes positively to the balance of payments. All of this suggests a need for policies to support the development of the sector through improvements in personal safety and tourism infrastructure in different parts of the country, wholesale tourism packages, diversification of tourism activity into the Amazon region, the development of adventure tourism and other measures.

\section{VIII \\ Training, labour flexibility and productivity}

In line with the theoretical arguments of Amadeo and Camargo (1996), the empirical evidence on Peruvian manufacturing industry (whose profile is close to the average for the tradable sector) suggests that the large rise in contractual instability has reduced average labour costs, but held back improvements in labour productivity. Consequently, the net effect on unit labour costs has been less than it might seem if only average labour costs were looked at. The reason is simple: increased occupational instability discourages companies from spending on training and thus holds back the growth of labour productivity (Chacaltana and García, 2002).

A large dose of contractual instability (which, as was seen in an earlier section, affected $79 \%$ of privatesector wage earners in 2000), and the fear of being made jobless that it entails, results in greater labourintensiveness and higher labour productivity. On the other hand, though, it discourages spending on training by companies, since in these circumstances they become less willing to invest in human capital and prefer to recruit trained workers from other firms. The net effect of increased occupational instability on productivity therefore has to be determined empirically.

Chacaltana and García (2002) found that manufacturing firms in Peru with a higher proportion of unstable employment contracts were $28 \%$ less likely to invest in training than those with a higher proportion of stable employment. They also showed empirically that companies which carried out training generated $25 \%$ more value-added per worker than those which did not, taking into account other variables such as business size, asset levels and branch of activity. Again, they found an elasticity (labour productivity in a firm /spending on training by the company) of close to 0.1 . In other words, a reduction (increase) of $50 \%$ in a company's training expenditure generated a fall (rise) of $5 \%$ in its labour productivity. Consequently, the effect that predominates is the negative net impact on productivity.

The empirical evidence, then, has far from negligible policy implications: insofar as the adverse effect on labour productivity prevails, the reduction of average labour costs caused by a significant increase in contractual flexibility is partially neutralized by the adverse effect this flexibility has on unit labour costs, owing to lower productivity growth.

In Peru, labour reform sought to reduce average hourly labour costs and facilitate labour management. In doing so, however, it ignored the implications for training and productivity. Lack of training thus became a constraint on overall productivity growth.

According to Chacaltana and García (2002), the evidence presented also raises a kind of conceptual paradox. To mobilize private investment a certain degree of labour flexibility is required. If this flexibility 
is too extreme, however, as it seems to have been in Peru, disincentives to training begin to arise, and thus obstacles to higher productivity and competitiveness.

How can the requisite dose of labour market flexibility be reconciled with the equally necessary investment in the human capital of workers which, as already pointed out, leads to higher productivity at the firm level?

There are at least three options, and they are not exclusive. The first is to have a public training system with wide access and high coverage, at no cost to companies. But this option requires fiscal resources on an enormous scale, and these are not available in Peru at present.

The second is to ensure that the length and characteristics of labour contracts established by labour institutions provide a time frame long enough to generate a reasonable return to firms' investment in training. The main thing here is that, both de jure and de facto, these regulations should not encourage average employment periods shorter than required for investment in training to be profitable. A far-reaching shift that reduces the average duration of employment contracts to a few months is tantamount to an assumption that investment in training can generate returns that will repay it in those few months, which is clearly unrealistic.

The third option is to create conditions that give firms the flexibility to raise productivity, something that not only acts as a buffer against external shocks, but requires a lesser degree of labour instability.

In addition, Chacaltana and García (2002) drew attention to a factor related to the economic context. In an economy that grows for short periods and then falls back into recession, many firms cannot plan for the long term. Consequently, the discount rates they use in their businesses are quite high, which means that they rule out any investment in training that offers a return lower than these rates. For this reason, it is crucial to generate expectations of high, permanent growth if companies are to be induced to invest more in training so that overall productivity can be raised.

\section{IX}

\section{External liberalization and microeconomic behaviour}

\section{External liberalization and productivity growth at the microeconomic level}

The liberalization of external trade and financing ought to have brought significant increases in overall productivity at the microeconomic level. It is important to reflect on why this did not happen, so that the lessons learned can be incorporated into the design of new proposals. García (2002b) indicates the factors that are listed below.

Firstly, a more open economy provides greater opportunities for information and knowledge about innovations than a more closed one, and it therefore offers a much more favourable environment for potential productivity growth. Edwards (1998) analysed the experience of 93 countries empirically and concluded that total factor productivity tended to increase more rapidly in an open economy than a closed one, since in an open economy there were greater opportunities for absorbing the technological progress generated by the leading countries; although he did not strictly identify causal factors, he pointed to the need for further empirical microeconomic research into liberalization of this kind and growth in total factor productivity. Regarding the latter, Baily and Solow (2001) prepared international productivity comparisons, conceptually based on the firm level, and concluded that the intensity of international (and domestic) competition had a strong impact on productivity. In the case of Peru, this must lead us to ask what factors have inhibited overall productivity growth at the microeconomic level. This subject will be returned to in the paragraphs that follow.

A second important aspect is the influence of export efforts. For exports to increase, productivity and competitiveness need to rise. But it is also a fact that an emphasis on exports requires a configuration that leads to productivity improvements. The effort to raise exports demands lower-cost and higher-quality products, storage, transport, communications and 
delivery. It also obliges companies to adapt to the markets and standards of more advanced countries. All this creates a requirement for higher productivity and quality that will spread through different segments of the economy as the export effort diversifies. But if this effort is confined to traditional enclaves (mining, industrial fishing and oil and gas in the case of Peru), the pressure for higher productivity will not spread.

The third aspect has to do with the way Peruvian businesses, many of which have no experience with external competitiveness, actually perceived the greater competitiveness demanded by liberalization. If the main approach to achieving competitiveness is the reduction of average labour costs through labour deregulation and cuts in non-wage labour costs, as it was in Peru in the 1990s, then there is no relationship between perception and reality, since not even a large fall in average labour costs would result in quality improvements and an appreciable and systematic decline in total unit costs year after year. Only a continuous rise in overall productivity can bring down costs in such a way. Thus, while the emphasis on cutting average labour costs seen in the 1990s was defensive in nature, it also acted as a "myth" that prevented the real problem from being perceived and incorporated into firms' policies, as a result of which no attention was paid to strategies for raising corporate competitiveness.

All this is of particular importance today. What should be done to dispel the myth and send Peruvian businesses a realistic message so that they can overcome the limitations of their approaches in the 1990s? The information on competitiveness indices supplied by the World Economic Forum bears out what has been said. In the Growth Competitiveness Index ranking, based on a sample of 80 countries, Peru dropped from number 54 to 57 in the 1999-2002 period. In the Microeconomic Competitiveness Index it fell from 47 to 68 , chiefly because of the worsening in the business environment and company strategies. ${ }^{8}$

Taking the decision to raise productivity at the microeconomic level is also important from the point of view of equity. Macroeconomic growth spreads more widely at the microeconomic level when productivity is rising than when adjustment is achieved through a reduction in average labour costs. The reason is simple: rising productivity allows real pay to

\footnotetext{
${ }^{8}$ See Cornelius (2003), Porter (2003) and World Economic Forum (http://www.weforum.org).
}

increase, whereas a strategy of reducing labour costs does not.

A fourth aspect is the following: in order to turn the potential offered by external liberalization into a systematic, permanent drive towards higher productivity, microeconomic decisions need to be aligned with this objective (Porter, 1998; Katz, 2000). This in turn means that businesses strategies (Porter, 2003) and institutions (Stiglitz, 1998; Katz, 2000) have to be pulling in the same direction at the microeconomic level. Perhaps the most important thing is to improve the business environment and the institutional fabric with a view to facilitating and stimulating a permanent drive for microeconomic productivity growth (Porter, 1998; Katz, 2000). The elements in the microeconomic environment that need to be improved or reformed are examined in Porter (2003), while García (2002a) explores institutional aspects of the microeconomy in the Peruvian experience. A market economy cannot work without institutions. Likewise, competitiveness cannot be adjusted through rising productivity, other than very slowly, unless there are institutions that stimulate this kind of decision-making.

Stiglitz (1998) spoke of the importance of applying new forms of institutional engineering and new models of public-private interaction if the aim was to create a firm basis for the new growth models, increase overall productivity more rapidly and make modernization more equitable. Porter (2003) argued that improving the business environment and company strategies was a key factor in raising productivity, while Katz (2000) also stressed the need to analyse microeconomic changes to understand what had happened with the emergence of the new open, marketoriented models.

Fifth, as well as creating a business and institutional environment that facilitates and stimulates productivity growth at the microeconomic level, there is a need to synchronize intermediate-level public policies to the same end. The typical example, absent from the Peruvian experience of the 1990s, is a set of policies to systematically improve workforce training and productivity.

\section{The Microeconomic Competitiveness Index and productivity growth}

In his analysis of how a country's enterprises operate, Porter (2003) identifies three stages. In the first, which is typical of the poorest countries (among which Porter 
includes Peru), competitiveness is based on cheap labour and use of the country's natural resources, while technology is introduced through imitation, importing, and direct investment. In the second stage, which is investment-driven and typical of middle-income countries, competitiveness results from improvements in the efficiency with which standard goods and services are produced; this stage is characterized by large infrastructure investments, government concern with the development of companies and strong incentives for private-sector investment and capital inflows, all of which results in higher productivity; goods and services become more sophisticated, but technological change still comes from outside, although the ability to adapt and improve foreign technology does exist. In the third stage, which is typical of highincome countries, the main source of competitiveness is skill at producing innovative goods and services at the global technology frontier, using the most advanced methods available; the business environment is characterized by strengths in a number of areas and by the existence of production chains and clusters.

Two remarks should be made here on Porter's (2003) argument, given its importance for the present work. The first is that the stages can be understood as processes in which certain factors gradually acquire critical mass, or disappear, as the result not of some historical law but of a variety of causes, among which are the effects of private and public policies. This means that changes in attitudes, ideologies and approaches to the development of firms, projected in the rules governing their conduct, have a real influence and effect.

The second is that Porter's (2003) analysis refers to countries. But in the many situations in Latin America where modern segments exist side-by-side with a range of unproductive traditional activities, this analysis is only valid for the modern segments of each country, which have the desire and ability to invest. Only for these does it make sense to speak of the sequential construction of interdependent capabilities at the microeconomic level. The structural heterogeneity emphasized by the Latin American structuralist school in the 1960s and 1970s is typical of many countries in Latin America, where modern and relatively developed segments continue to exist alongside others that are very far from being modern. What this means is that if the focus is on a country's modern, structured sector, for which microeconomic modernization strategies make sense, then the factors influencing competitiveness, the degree of organization and per capita GDP will not correspond to the average for the country as a whole. Consequently, it is the data for modern segments and not the averages for the country that are relevant when the most appropriate competitiveness strategy is being sought.

An example of this does in fact emerge from Porter (2003), whose figure 6 correlates the distribution of the Microeconomic Competitiveness Index by country with the distribution of per capita GDP by country in 2001, adjusted for purchasing power parity. In that chart, Brazil has a Microeconomic Competitiveness Indicator slightly lower than Tunisia's, while Mexico is below Croatia, Namibia, Jordan and Morocco. The thing is that the indicators used to construct this index are for the country as a whole, while in the cases of Brazil and Mexico it would make more sense to use those for their modern segments. The same is true of Peru. According to the chart referred to, Peru's Microeconomic Competitiveness Index is lower than that of Jordan, Botswana, Namibia, Vietnam, Morocco, El Salvador and Tunisia, and this is because the indicators taken as the basis and normalized for the country are only relevant to the modern segment of the Peruvian economy. The same thing happens when we consider Peru's per capita GDP. In the late 1990s this was about 4,650 1994 soles (about US\$2,400), but an estimation of GDP per capita in the modern segment, which is what counts for the analysis of competitiveness, yields a figure almost three times as high. The implication is clear: if per capita GDP in the modern segment is considered, Peru classifies as a middle-income country, so that Porter's analysis places it at the stage where investment should have contributed to higher productivity, and not at the stage where competitiveness depends solely on cheap labour.

Taking all the above into account, the modern segments of the Peruvian economy certainly could have moved into the second stage in the 1990s. What prevented them was a narrow view of competitiveness, confined to the reduction of labour costs, that caused serious social harm and had even more serious economic consequences. The question now is how this view can be changed. 


\section{X}

\section{Policies to raise overall productivity}

This section will review the type of proposals that have been formulated for improving overall productivity.

Porter (2003) describes a set of microeconomic factors to which priority needs to be given because of their effect on firms' competitiveness, grouping them as follows: i) factors that determine the microeconomic environment, such as physical infrastructure (particularly important in Peru), administrative infrastructure, the quality of human resources, the legal and judicial system, technological infrastructure, the development of financial markets, the regulatory framework for investment, incentives for competitiveness, trade barriers and the intensity of domestic competition; and ii) factors that influence company strategies, such as the nature of their competitive advantage, the sophistication of production processes, staff training, marketing, the delegation of decision-making, foreign market penetration, innovation capacity and the professionalism of management.

García (2002a) argues for changes in the institutional and economic framework influencing microeconomic decision-making, including:

i) Gradually replacing the dominant collective bargaining model with one that, in addition to the usual issues of wage purchasing power and social protection, takes in:

- aspects and commitments on both sides that raise corporate productivity, and

- pay incentives for productivity that link real pay rises to productivity increases.

ii) Developing the necessary institutions so that productivity-raising practices and behaviour can gradually be spread to medium-sized and small businesses.

iii) Strengthening and modernizing the enforcement of employment legislation to bring down the very high proportion of wage earners without contracts; for reasons of efficiency, this will probably have to be accompanied by stricter enforcement of companies' compliance with their direct and indirect tax obligations.

iv) Implementing active policies to foster and finance technological innovation. Given that most of the countries competing with Peru now have policies of this kind, the lack of them in Peru is yet another factor holding the country back where productivity improvements are concerned. The idea should be not to give up on a strategy based on valuable natural resources, but to add value to these resources by processing them and pursuing innovation. This will also help to lay the groundwork for a gradual shift towards an innovation-based competition model, via the adaptation of innovations from abroad. Since Peru is part of a world that is moving towards competition in knowledge- and innovationintensive products and services, our proposal is that a competitive fund should be created for innovations and other measures to stimulate and facilitate innovation in companies, generate critical mass in technology and university centres and, above all, link these segments together. The fund would lend money to finance the initial development and testing stage for innovations.

v) Fostering a training services market and establishing a regulatory framework for this. To this end, the following is proposed: create a national training council and establish by law a regulatory framework for the training services market; establish a national training fund; encourage the development of high-quality providers for this market; orient this market towards training by competency; establish a quality certification system for training services providers; develop a method for evaluating and certifying the usefulness of providers and their services; make far greater use of in-house training and help spread productivity-raising practices; establish tax incentives for companies to invest in occupational training and in enhanced productivity and quality management; and, following Sierra and Sato (2002), increase the resources for subsidizing "bonopymes" (vouchers entitling small and medium-sized enterprises to discounts on business development services), but target their use on productivity management training. According to Chacaltana and García (2002), in-house training contributes significantly to higher productivity at the microeconomic level. In fact, it is not just a question of improving inhouse training. Companies also need to adopt new 
working practices and more advanced ideas about human resources management, communicate more with their workers, provide ongoing training, and translate all this into pay incentives. It is all this, in combination with more in-house training, that results in significant productivity increases. ${ }^{9}$

vi) Encouraging small and medium-sized enterprises to form clusters or production chains, or to link up with production networks led by larger companies, as the current state of SME development dictates. Combined with greater access to resources, all such links help raise productivity, so that removing

\section{XI}

\section{Conclusions}

This article stresses that the idea of attaining competitiveness by reducing average labour costs, which was pursued in the 1990s and still persists in Peru, has not only failed to generate returns sufficient for a sustained increase in private-sector investment in non-extractive tradable sectors, but has masked the need for essential measures to improve productivity in Peruvian companies: i) a stable, competitive real exchange rate at the initiation stage, and ii) steady growth in overall productivity at the microeconomic level. The question now is how the macroeconomic regime and microeconomic decision-making can be gradually reoriented in the directions described. It is in this context that the following conclusions should be read.

\section{Competitiveness, the real exchange rate and overall productivity at the microeconomic level}

Since the late 1970s, productivity has gradually ceased to be an exogenous variable and increasingly become a policy variable, capable of being altered for the better by private and public actions. This has happened in both developed and emerging economies, albeit in different ways. In the present situation, when the most profound technological and organizational revolution in history is taking place, this potential for influence has gradually led to a general acceptance that in a

\footnotetext{
${ }^{9}$ See Ichniowski, Shaw and Prennushi (1995).
}

obstacles to the development of such clusters, chains or networks is a very effective way of improving the competitiveness of the SMEs that make them up. The Government of Peru is already implementing initiatives of this kind, and it would be very helpful for it to enhance them by facilitating the development of systems that pooled information on markets, suppliers, benchmarking systems and best practice among SMEs. These measures are far more significant than they might appear, as most Peruvian companies are small or medium-sized.

globalized environment improved competitiveness can only come from higher overall productivity.

Two things stand out here. The first is that for productivity improvements to be achieved at the microeconomic level, it is necessary for companies to be willing to invest (in innovations, training, equipment, etc.), particularly in tradable sectors. A macroeconomic regime in which there is a stable, competitive real exchange rate during the long initiation period can guarantee the returns needed to speed up investment decisions in these sectors.

The second thing is that a regime of this type should serve to buy time for the maturation process that is needed before the effects of policies to raise overall productivity at the microeconomic level make themselves felt.

To correctly ascertain the competitiveness criterion that is right for a country like Peru, due weight should be given to the fact that there, as in many other Latin American countries, modern and relatively developed sectors continue to exist side by side with very backward ones. This means that in considering what microeconomic modernization strategies make sense for the country's modern, structured segments, it is the data for these segments, and not the average data for the whole country, that should be used to assess the most appropriate competitiveness strategy. It is on this basis that the reduction of labour costs can be rejected as the sole method of raising competitiveness, and that a central thesis of this paper can be accepted: that competitiveness improves as 
overall productivity at the microeconomic level rises, in the context of what Porter (2003) calls the "investment-driven stage".

The approach suggested - a stable, competitive real exchange rate and higher total microeconomic productivity - does not mean that reducing non-wage labour costs cannot make a contribution, but it does place it in a more realistic light.

\section{The real exchange rate, productivity, exports and employment}

A competitive real exchange rate at the initiation stage and a sustained rise in overall productivity in tradable sectors at the microeconomic level are the basis for competitiveness. But for high-quality employment to grow at the rates desired, demand for tradable and nontradable products needs to grow far more quickly than productivity. With a stable, competitive real exchange rate, higher demand initially depends on growth in exports and in output that competes with imports. To make faster progress in this area, then, there is a need for export support policies and trade agreements. Higher output and investment in tradable sectors will gradually help, both directly and indirectly, to dynamize domestic demand for goods that replace imports. Investment in tradable sectors can grow rapidly and, if appropriate linkage policies are applied, induce a faster rate of economic growth in the aggregate and a significant rise in high-quality employment in modern sectors. In turn, higher employment and wages (the latter due to productivity improvements) will dynamize domestic demand. In consequence, the best employment policy is to combine measures for maintaining a competitive real exchange rate and raising overall productivity and product quality at the microeconomic level, on the one hand, with measures for speeding up export growth yet further, on the other.

\section{Microeconomic institutions}

To take advantage of the access to innovations that an open economy offers, it is necessary not only to apply the "right" macroeconomic policy but also to create an appropriate microeconomic environment and, above all, to establish an institutional context that facilitates adoption of innovations at the microeconomic level. To put it another way, it is vital to have an institutional context (understood as a set of ground rules that govern the behaviour of firms) which impacts the microeconomic level and encourages the adoption of productivity-raising policies there.

An important corollary of this is that the institutional system of incentives should not obstruct the adoption of microeconomic strategies for improving productivity, as was the case in Peru in the 1990s, when microeconomic strategies were skewed towards the reduction of average labour costs while the need for overall productivity improvements was removed from the business agenda.

\section{Flexibility in labour markets and the flexibility to raise productivity}

In 1990-2003, the Peruvian labour reform and the swing of the pendulum away from decades of employment protection led to behaviours that in practice went further than the reform intended. Whether because of ingenuousness on the part of policy makers, or because of neglect, the result was a large increase in low-quality employment in the labour market, with an excess of unstable, unprotected contracts arising from of the shift of private employment towards wage earners without labour contracts. This lowered employment standards and increased social conflict. It also held back spending on training by companies, thereby constraining overall productivity growth. The worst thing was that the emphasis on reducing average labour costs blinded decision makers to the country's real sources of competitiveness. The most damaging part of this was that it took the competitiveness debate into an area that was not just irrelevant, but economically ineffective and socially disruptive as well, and convinced the main actors, Peruvian businesses, that it was the one that mattered. Thus, one of the greatest tasks ahead is to explain to businesses that the approach which predominated in the 1990s gradually needs to be replaced by a strategy for raising microeconomic and mesoeconomic productivity. This entails keeping real labour costs aligned with microeconomic productivity growth and bringing in a competitive real exchange rate.

Consequently, what economic policy needs to clarify in this area is:

i) what concrete measures can be taken to phase out the old labour flexibility, whose usefulness as a competitiveness strategy is now over, and instead foster "flexibility in the production process to increase overall productivity" under the umbrella of a stable, competitive real exchange rate during the ignition period of this strategy; and 
ii) how the transition from one approach to competitiveness to the other can be effected, which involves combining empirically the general flexibility needed to raise productivity, on the one hand, and the margin of labour market flexibility that companies actually need, on the other, since in practice a country's competitiveness depends on this mix.

Without a macroeconomic regime that includes a stable, competitive real exchange rate, microeconomic strategies to raise productivity and an aggressive policy for diversifying exports and signing trade agreements, it is unlikely that there will be any significant increase in competitiveness, private investment or high-quality employment.
The arguments put forward in this article differ from the usual recommendations for Peru, heard from both within and beyond the country, which continue to stress the reduction of average labour costs. What is being argued here is that the best employment policy is a determination to extend and diversify external markets and to continually improve competitiveness through a competitive real exchange rate and rapidly growing productivity, particularly in the non-extractive tradable sector. Although this might look contradictory from a traditional economic perspective, it is after all consistent with what common sense would suggest for a small, open economy in a context of globalization and at a stage in history characterized by the quality and variety of innovations available.

\section{Bibliography}

ADC (Andean Development Corporation) (2002): Obstáculos al aumento de la productividad en el Perú, Caracas, unpublished.

Amadeo, E. and J.M. Camargo (1996): Labour flexibility, productivity and adjustment, in J.B. Figuereido (ed.), Las instituciones laborales frente a los cambios en América Latina, Geneva, International Institute for Labour Studies (IILS)/ International Labour Organization (ILO).

Aráoz, M. (2002): Perspectivas de la política arancelaria y de integración, Economía y sociedad, No. 48, Lima, InterAmerican Economic and Social Council (CIES).

Baily, M. and R. Solow (2001): International productivity comparisons built from the firm level, Journal of Economic Perspectives, vol. 15, No. 3, Nashville, Tennessee, American Economic Association.

Ball, L. (1998): Policy Rules for Open Economies, NBER Working Paper, No. 6760, Cambridge, Massachusetts, National Bureau of Economic Research (NBER).

Cornelius, P. (2003): Growth Competitiveness Report, 2003, www.worldeconomicforum.org.

Chacaltana, J. (2002): El desarrollo del sector turismo y el empleo, Red de políticas de empleo, Lima, Inter-American Economic and Social Council (CIES).

Chacaltana, J. and N. García (2002): Estabilidad laboral, capacitación y productividad, Red de políticas de empleo, Lima, Inter-American Economic and Social Council (CIES).

De Ferranti, G. and others (2003): Cerrando la brecha en educación y tecnología, Washington, D.C., World Bank.

Edwards, S. (1998): Openness, productivity and growth: what do we really know?, The Economic Journal, vol. 108, No. 447, Oxford, Blackwell Publishing, March.

Frenkel, R. (2004): La política macroeconómica para el crecimiento y el empleo, Estrategia de crecimiento y empleo en el Mercosur, Lima, International Labour Organization (ILO), April, preliminary version.

García, N. (2004): Estrategia de crecimiento y empleo: el enfoque, Estrategia de crecimiento y empleo en el Mercosur, Lima, International Labour Organization (CIES), April, preliminary version.

(2002a): Productividad, competitividad y empleo, Lima, Inter-American Economic and Social Council (CIES). (2002b): La calidad del empleo en el Perú, Red de políticas de empleo, Lima, Inter-American Economic and Social Council (CIES).

Iguiñiz, J. (2001): Desarrollo económico reciente del Perú, Pobreza $y$ desarrollo en el Perú, Lima, Oxford Famine Relief Organization (OXFAM).

Ichniowski, C., K. Shaw and G. Prennushi (1995): The Effects of Human Resource Management Practices on Productivity, NBER Working Paper, No. W5333, Cambridge, Massachusetts.

INEI (Instituto Nacional de Estadística e Informática) (2004): Cuentas nacionales del Perú, www.inei.gob.pe, April.

IPE (Instituto Peruano de Economía) (2001): Productividad y crecimiento económico en el Perú, Lima, May.

(2002a): Estado actual de la infraestructura de servicios públicos: estimación de la brecha de inversión, Lima. (2002b): Impacto de la infraestructura de servicios públicos sobre la productividad de la economía peruana, Lima.

Katz, J. (2000): Reformas estructurales, productividad y conducta tecnológica, Santiago, Chile, Fondo de Cultura Económica (FCE)/Economic Commission for Latin America and the Caribbean (ECLAC).

Martínez, D. and V. Tokman (1997): Costo laboral y competitividad en el sector manufacturero de América Latina, Costos laborales y competitividad industrial en América Latina, Geneva, International Labour Organization (ILO).

(1999): Costos laborales y productividad: estrategias para la competitividad, Inseguridad laboral y competitividad, Lima, International Labour Organization (ILO).

Moguillansky, G. (1996): The macroeconomic context and investment: Latin America since 1980, CEPAL Review, No. 58, LC/G.1916-P, Santiago, Chile, April.

Porter, M. (1998): The Competitive Advantage of Nations, New York, The Free Press.

(2003): Building the Microeconomic Foundations of Prosperity: Findings from the Microeconomic Competitiveness Index, www.worldeconomicforum.org.

Rodrik, D. (2003): Growth Strategies, NBER Working Paper, No. 10050, Cambridge, Massachusetts, National Bureau of Economic Research (NBER).

Sierra, J. and E. Sato (2002): Políticas para mejorar la calidad del empleo en las PYMES, Red de políticas de empleo, Lima, InterAmerican Economic and Social Council (CIES). 
Stiglitz, J. (1998): Más instrumentos y metas más amplias para el desarrollo: hacia el consenso post-Washington, Desarrollo económico, vol. 38, No. 151, Buenos Aires, Institute of Economic and Social Development, October-December.

Svarzman, G. (2004): La política de exportaciones y la integración en el MERCOSUR, Estrategia de crecimiento y empleo en el
MERCOSUR, Lima, International Labour Organization (ILO), April, preliminary version.

Williamson, J. (2003): Exchange rate policy and development, Initiative for Policy Dialogue (IPD), Columbia, University of Columbia. 